\title{
Thermal Stability in the Blended Lithium Manganese Oxide - lithium Nickel Cobalt Manganese Oxide Cathode Materials: An in situ Time-resolved X-Ray Diffraction and Mass Spectroscopy Study
}

Enyuan $\mathrm{Hu}^{\dagger}$, Seong Min Bak ${ }^{\dagger}$, Sanjaya D. Senanayake ${ }^{\dagger}$, Xiao-Qing Yang ${ }^{\dagger}{ }^{*}$, Kyung-Wan Nam ${ }^{\|, *}$, Lulu Zhang $\$$, Minhua Shao,

${ }^{\dagger}$ Chemistry Department, Brookhaven National Laboratory, Upton, New York 11973

|| Department of Energy and Materials Engineering, Dongguk University-Seoul, 26 Pil-dong, 3ga, Jung-gu, Seoul, 100-715, Republic of Korea

${ }^{\$}$ Department of Chemical and Biomolecular Engineering, The Hong Kong University of Science and Technology, Clear Water Bay, Kowloon, Hong Kong

* xyang@bnl.gov; Tel.: +001-6313443663; knam@dongguk.edu; Tel.: +82-02-2260-4978; kemshao@ust.hk; Tel.: +852-34692269

\begin{abstract}
Thermal stabilities of a series of blended $\mathrm{LiMn}_{2} \mathrm{O}_{4}(\mathrm{LMO})-\mathrm{LiNi}_{1 / 3} \mathrm{Co}_{1 / 3} \mathrm{Mn}_{1 / 3} \mathrm{O}_{2}(\mathrm{NCM})$ cathode materials with different weight ratios were studied by in situ time-resolved x-ray diffraction (XRD) combined with mass spectroscopy in the temperature range of $25^{\circ} \mathrm{C}$ to $580^{\circ} \mathrm{C}$ under helium atmosphere. Upon heating, the electrochemically delithiated LMO changed into $\mathrm{Mn}_{3} \mathrm{O}_{4}$ phase at around $250^{\circ} \mathrm{C}$. Formation of $\mathrm{MnO}$ with rock-salt structure started at $520^{\circ} \mathrm{C}$. This observation is in contrast to the previous report for chemically delithiated LMO in air, in which a process of $\lambda-\mathrm{MnO}_{2}$ transforming to $\beta-\mathrm{MnO}_{2}$ was observed. Oxygen peak was not observed in all cases, presumably as a result of either consumption by the carbon or detection limit. $\mathrm{CO}_{2}$ profile correlates well with the phase transition and indirectly suggests the oxygen release of the cathode. Introducing NCM into LMO has two effects: first, it makes the high temperature rock-salt phase formation more complicated with more peaks in $\mathrm{CO}_{2}$ profile due to different $\mathrm{MO}(\mathrm{M}=\mathrm{Ni}, \mathrm{Mn}$, Co) phases; secondly, the onset temperature of $\mathrm{CO}_{2}$ release is lowered, implying lowered oxygen
\end{abstract}


release temperature. Upon heating, XRD patterns indicate the NCM part reacts first, followed by the LMO part. This confirms the better thermal stability of LMO over NCM.

Keywords: Lithium-ion batteries, structural evolution, thermal stability, phase transformation, gas evolution

\section{Introduction}

Lithium ion batteries (LIBs) have been used as power sources for portable electronic systems for decades. Recently, their applications have been expanded to electric vehicles (EVs). The applications in EVs meet many new challenges, such as safety characteristics, high power and high energy densities. To optimize the performance of the batteries, some battery manufacturers developed cells using a mixture of two different active materials in their cathodes. This approach takes advantages of combined good properties of each material. By blending the active materials, some shortcomings of component materials can be minimized. Therefore, the mixtures can be tailored to have higher power/energy densities, enhanced stability and lower $\operatorname{cost}^{1-7}$. One successful example is the mixture of spinel $\mathrm{LiMn}_{2} \mathrm{O}_{4}(\mathrm{LMO})^{8}$ and layered $\mathrm{LiNi}_{1 / 3} \mathrm{Co}_{1 / 3} \mathrm{Mn}_{1 / 3} \mathrm{O}_{2}$ $(\mathrm{NCM})^{9,10}$. The spinel LMO component can contribute advantages to low cost, good thermal stability even at charged state, and high electronic and ionic conductivities, but suffers from low capacity. The layered NCM component can contribute to high capacity but suffers from poorer ionic conductivity and thermal stability.

Dahn et al ${ }^{11}$ has investigated the thermal stability of chemically delithiated LMO in air. They found that it is very stable against decomposition up to $500{ }^{\circ} \mathrm{C}$. Yabuuchi et al ${ }^{12}$ have investigated the thermal stability of overcharged NCM and concluded that it is much more 
thermally stable than its counterparts of $\mathrm{LiCoO}_{2}$ and $\mathrm{LiNiO}_{2} \cdot \mathrm{Luo}^{13-16}$ et al have investigated the role of $\mathrm{Al}, \mathrm{Mg}$ and $\mathrm{Zr}$ on improving the thermal stability of NCM. Structural changes of the charged layer-structured cathode materials such as $\mathrm{Li}_{1-\mathrm{x}} \mathrm{NiO}_{2}, \quad \mathrm{Li}_{1-\mathrm{x}} \mathrm{Ni}_{0.5} \mathrm{Mn}_{0.5} \mathrm{O}_{2}$, $\mathrm{Li}_{1-\mathrm{x}} \mathrm{Ni}_{0.8} \mathrm{Co}_{0.15} \mathrm{Al}_{0.05} \mathrm{O}_{2}$, and $\mathrm{Li}_{1-\mathrm{x}} \mathrm{Ni}_{1 / 3} \mathrm{Co}_{1 / 3} \mathrm{Mn}_{1 / 3} \mathrm{O}_{2}$ during heating with and without presence of electrolyte have been systematically investigated by Yoon et al using synchrotron based in situ time-resolved X-ray diffraction $(\mathrm{TR}-\mathrm{XRD})^{17-19}$. It has been demonstrated that the presence of electrolyte accelerated thermal decomposition of the charged cathode material by lowering the temperatures for onset of the reactions. Thermal stability of blended material has been examined by some researchers, focusing on the reactivity of charged cathode with electrolyte using calorimeter measurement. However, more studies are needed to understand thermal stability from structural point of view ${ }^{3,20}$. Recently, an in situ synchrotron X-ray diffraction coupled with mass spectroscopy (XRD-MS) technique has been developed and applied to monitor both the structural changes and gas evolution during heating ${ }^{21-23}$. Here, we report the results on a series of blended LMO-NCM cathode materials with different weight ratios to correlate the thermal stability with the composition. These results are important for optimizing the compositions of blended materials for practical applications.

\section{Experimental}

The LMO and NCM powders were provided by a commercial source and were mixed thoroughly in a mortar. The compositions of starting materials are $\mathrm{LiMn}_{2} \mathrm{O}_{4}$ (LMO) and $\mathrm{LiNi}_{1 / 3} \mathrm{Co}_{1 / 3} \mathrm{Mn}_{1 / 3} \mathrm{O}_{2}$ (NCM). Weight ratios (LMO to $\mathrm{NCM}$ ) of 1:0, 3:1 and 1:1 were investigated. Cathodes were fabricated using $80 \%$ of active materials, $10 \%$ of carbon black (Chevron), and $10 \%$ of PVDF (Kureha) and slurry-casted onto an Al foil current collector. 2032-type coin cells were assembled using a Li foil anode, a separator (Celgard), and an electrolyte containing 1.2 $\mathrm{M} \mathrm{LiPF}_{6}$ 
in EC (ethyl carbonate) and a DMC (dimethyl carbonate) solution (3:7 EC/DMC volume ratio). For the electrochemical cycling test, the coil cells were charged at a $\mathrm{C} / 10$ rate, assuming a theoretical capacity of $160 \mathrm{mAh} \mathrm{g}^{-1}$.

Cells were charged to $4.3 \mathrm{~V}$ and disassembled in a glove box. Electrodes were carefully scratched off the current collector, washed thoroughly in a DMC solvent and sealed in a vial. Then samples were transferred to the beamline where they were loaded into a glass capillary with an inner diameter of $0.7 \mathrm{~mm}$. One end of the capillary (i.e., the inlet) was connected to an He- carrier gas source and the other end (i.e., the outlet) was connected to a residual gas analyzer/mass spectrometer (RGA200, Stanford Research Systems). The TR-XRD data were collected using the thermal stage at beamline X7B $(\lambda=0.3196 \AA)$ of the National Synchrotron Light Source (NSLS) in the transmission mode, while the MS signals were simultaneously collected when the sample was heated from room temperature to $600{ }^{\circ} \mathrm{C}$ at a rate of $\sim 2.0{ }^{\circ} \mathrm{C} \mathrm{min}-$

${ }^{1}$. Each XRD pattern takes about 4 minutes, corresponding to $8{ }^{\circ} \mathrm{C}$ temperature ambiguity for each XRD scan. Details of the preparation method were described in our previous publications ${ }^{11-}$ 13. To ease comparisons with other published results using conventional x-ray sources, we plotted the XRD patterns using converted $2 \theta$ angles corresponding to the $\mathrm{Cu} \mathrm{K} \alpha(\lambda=1.54 \AA)$ radiation wavelength. The XRD data was fitted using GSAS-EXPGUI software ${ }^{24,25}$.

\section{Results and Discussion}

Charging profiles for blended materials with different weight ratios (LMO to NCM) of 1:0, 3:1 and 1:1 are shown in Fig. 1. It can be seen that as the NCM content increases, the capacity increases with the same cutoff voltage of $4.3 \mathrm{~V}$. This can be explained by the result from the 
literature $^{4}$ : NCM mainly contributes to the capacity below $4.0 \mathrm{~V}$ and LMO to the capacity between $4.0 \mathrm{~V}$ and $4.3 \mathrm{~V}$; so when there is more $\mathrm{NCM}$ in the material, the low voltage part $(<4.0$ $\mathrm{V})$ is increasingly activated. If we assume the pure LMO sample was fully delithiated at $4.3 \mathrm{~V}$ to reach a composition of $\mathrm{Li}_{0.0} \mathrm{Mn}_{2} \mathrm{O}_{4}$, and use the partial capacity obtained between $4.0 \mathrm{~V}$ and 4.3 $\mathrm{V}$ to calculate the lithium contents of LMO in charged state in the two mixtures, the compositions of $\mathrm{Li}_{0.1} \mathrm{Mn}_{2} \mathrm{O}_{4}$ and $\mathrm{Li}_{0.05} \mathrm{Mn}_{2} \mathrm{O}_{4}$ for d-LMO in 3:1 and 1:1 mixtures were obtained respectively. Using similar method for the partial capacity below $4.0 \mathrm{~V}$, the compositions of $\mathrm{Li}_{0.54} \mathrm{Ni}_{1 / 3} \mathrm{Co}_{1 / 3} \mathrm{Mn}_{1 / 3} \mathrm{O}_{2}$ and $\mathrm{Li}_{0.52} \mathrm{Ni}_{1 / 3} \mathrm{Co}_{1 / 3} \mathrm{Mn}_{1 / 3} \mathrm{O}_{2}$ were obtained for d-NCM in 3:1 and 1:1 mixtures respectively. It is noticed that the 1:1 mixture delivered more specific capacity than the 3:1 mixture but the delithiation status of the d-NCM component stayed almost unchanged. This is because the additional specific capacity in 1:1 mixture was mainly contributed by the higher percentage of NCM, not the deeper delithiation. To confirm our results, we also used lattice parameters to estimate the degree of delithiation. Le Bail fittings were carried out for 3:1 mixture and 1:1 mixture at charged states to obtain the lattice parameter information for the NCM component. For the 3:1 mixture, the lattice parameters for $\mathrm{d}-\mathrm{NCM}$ are $\mathrm{a}=2.8221 \AA$ and $\mathrm{c}=$ 14.5251 $\AA$; while for the $1: 1$ mixture, the lattice parameters for $\mathrm{d}-\mathrm{NCM}$ are $\mathrm{a}=2.8200 \AA$ and $\mathrm{c}=$ 14.5225 $\AA$. Based on results in the literature ${ }^{26}$, the delithiation status for both mixtures should be somewhere between $\mathrm{Li}_{0.6} \mathrm{Ni}_{1 / 3} \mathrm{Co}_{1 / 3} \mathrm{Mn}_{1 / 3} \mathrm{O}_{2}$ and $\mathrm{Li}_{0.52} \mathrm{Ni}_{1 / 3} \mathrm{Co}_{1 / 3} \mathrm{Mn}_{1 / 3} \mathrm{O}_{2}$, which are in good agreement with what we estimated from the specific capacity.

In situ XRD-MS data for the charged spinel LMO is shown in Fig. 2a. A LeBail fitting of the high temperature $\left(580{ }^{\circ} \mathrm{C}\right.$ ) XRD pattern (Fig. 2b) indicates the formation of both $\mathrm{Mn}_{3} \mathrm{O}_{4}$ and $\mathrm{MnO}$ phases, with the former being the dominant one. $\mathrm{Mn}_{3} \mathrm{O}_{4}$ has the spinel structure with divalent manganese ions and trivalent manganese ions occupying tetrahedral and octahedral sites 
respectively $^{27-29}$. Because of the cooperative Jahn-Teller distortion of trivalent manganese ions, symmetry of $\mathrm{Mn}_{3} \mathrm{O}_{4}$ is lowered from cubic to tetragonal, giving rise to considerably more Bragg peaks in the XRD pattern than cubic spinel. For MnO, it has the rock salt structure ${ }^{30,31}$, which can be regarded as Mn filling all octahedral sites in the cubic-closed-packed oxygen framework. With characteristic peaks identified for each high temperature product, the whole structure change process shown in Fig. 1a can be divided into four stages. In the first stage between room temperature and $225{ }^{\circ} \mathrm{C}$, only thermal expansion of $\lambda-\mathrm{MnO}_{2}{ }^{32}$ lattice is observed. In the second stage between $200{ }^{\circ} \mathrm{C}$ and $400{ }^{\circ} \mathrm{C}, \mathrm{Mn}_{3} \mathrm{O}_{4}$ starts to form at around $225{ }^{\circ} \mathrm{C}$. As explained previously, this phase features divalent manganese occupying tetrahedral sites. Therefore, its formation suggests that manganese was slightly reduced. This coincides with the $\mathrm{CO}_{2}$ peak between $200{ }^{\circ} \mathrm{C}$ and $400{ }^{\circ} \mathrm{C}$. In this temperature region, oxygen released from the original framework likely reacts with carbon or organic binder in the sample to form $\mathrm{CO}_{2}$. The multiple peaks in $\mathrm{CO}_{2}$ profile suggest that the decomposition reaction is not a single process in this region. The third stage is featured by the formation of $\mathrm{MnO}$ rock salt, which is between $425{ }^{\circ} \mathrm{C}$ and $525{ }^{\circ} \mathrm{C}$. It can be seen that the growth of $\mathrm{Mn}_{3} \mathrm{O}_{4}$ and $\mathrm{MnO}$ in this stage accompanies the composition of $\lambda-\mathrm{MnO}_{2}$. In the fourth stage above $525^{\circ} \mathrm{C}, \lambda-\mathrm{MnO}_{2}$ is depleted and only $\mathrm{MnO}$ and $\mathrm{Mn}_{3} \mathrm{O}_{4}$ remain. Our results are not quite the same as those reported by Dahn et al ${ }^{11}$ about heating chemically delithiated LMO. In their report, chemically delithiated LMO, or $\lambda-\mathrm{MnO}_{2}$, transformed to $\beta-\mathrm{MnO}_{2}$ upon heating up to $500{ }^{\circ} \mathrm{C}$ without any oxygen loss and decomposition afterwards. The discrepancy might be attributed to different experimental conditions. For example, while chemical delithiation was employed in Dahn's experiment, LMO was electrochemically delithiated in this study. This implies that carbon and binder used in the electrode in this study may have significant effects on the thermal stability of $\lambda-\mathrm{MnO}_{2}$. Our 
experimental conditions are chosen to simulate the real battery electrode operation conditions more closely, where active materials were mixed with carbon and binder. Based on this comparison, it can be proposed that carbon and binder may react with most of the slowly released oxygen from the spinel, giving $\mathrm{CO}_{2}$ peaks but making $\mathrm{O}_{2}$ release undetectable. Therefore, it seems that the carbon sources in a cell are likely to facilitate the reduction of electrode material and complicate the phase transition route. It should be noted that presence of electrolyte can also have major impact on the thermal stability of cathode materials as evidenced by Chen et $\mathrm{al}^{33,34}$. However, as described in the experimental section, we thoroughly washed out electrolytes from the sample using a DMC solvent since the experimental setup was specifically designed for monitoring the crystal structural evolution and product gas evolution simultaneously. We have also confirmed in our previous work that the effect of residual DMC solvent that may exist at the sample surface on the MS signal was negligible ${ }^{23}$. Combing results from our experiments and those in the literature, it can be concluded that carbon, binder and electrolyte all can act as reducing agent, deteriorating the thermal stability of charged cathode materials and contributing to an early oxygen release.

Figure 3a shows the XRD-MS results for the mixture with a weight ratio of LMO:NCM $=3: 1$. In terms of phase transition, it differs from that of pure LMO in three major aspects, namely, high temperature phases, phase transition route and $\mathrm{CO}_{2}$ release profile. First, a close look at the XRD pattern at $580{ }^{\circ} \mathrm{C}$ reveals two kinds of rock-salt phases rather than the one in LMO formed at high temperature (Fig. 3c). The one with a lattice parameter of $4.46 \AA$ is the same as the $\mathrm{MnO}$ in Fig. 2 while the other one has a lattice parameter of $4.32 \AA$, shorter than the $4.46 \AA$ for $\mathrm{MnO}$ but longer than the $4.29 \AA$ and $4.16 \AA$ for $\mathrm{CoO}$ and $\mathrm{NiO}$, suggesting a solid-solution type rocksalt phase. It is denoted as ( $\mathrm{Mn}, \mathrm{Co}, \mathrm{Ni}) \mathrm{O}^{35,36}$. This assignment is supported by the fact that in 
the $\mathrm{CO}_{2}$ profile, multiple peaks were observed at high temperatures for this mixture, in contrast to that for LMO, where only a singular peak was observed. Secondly, as can be seen from the third stage Fig. 3a, rock-salt phases were formed through the decomposition of $\mathrm{Mn}_{3} \mathrm{O}_{4}$ only, after all d-LMO and d-NCM were converted to $\mathrm{Mn}_{3} \mathrm{O}_{4}$. This is in contrast to the LMO case. In that case, rock salt phase peaks already appeared even before the $\lambda-\mathrm{MnO}_{2}$ phase peaks had disappeared. These facts suggest that for LMO, the rock-salt phase (MnO) mainly grows at the expense of $\lambda-\mathrm{MnO}_{2}$ in third stage and continues to grow at the expense of $\mathrm{Mn}_{3} \mathrm{O}_{4}$ in fourth stage. Such difference might be caused by the fact that d-LMO and d-NCM were not fully delithiated while $\lambda-\mathrm{MnO}_{2}$ was fully delithiated. Thirdly, the onset temperature of $\mathrm{CO}_{2}$ release is lowered from above $200^{\circ} \mathrm{C}$ in d-LMO's case to around $175^{\circ} \mathrm{C}$. This is presumably caused by the introduction of $\mathrm{Ni}$ in $\mathrm{NCM}$, whose tetravalent form is very unstable and therefore leads to an early oxygen release. It should be noted that while Ni can deteriorate the thermal stability of layered materials, Co can play the stabilizing role as evidenced by recent experimental results ${ }^{22}$, ${ }^{23}$. By indexing the XRD pattern before heating, it is possible to identify which part contributes to the early stage oxygen release (Fig. 3b). Interestingly, it is clearly seen that peaks from the hexagonal phase are gradually disappearing while those from the cubic phase still remain as temperature is increased in the early stage of heating. This indicates the NCM part reacts first, suggesting its poorer thermal stability than the LMO.

When the weight ratio of LMO to NCM reaches $1: 1$, low temperature $\left(<500{ }^{\circ} \mathrm{C}\right)$ thermal stability doesn't seem to be affected much by introducing higher percentage of NCM. As shown in Fig. 4a, the reaction can be similarly divided into three stages as those in Fig. 3a. Following the stages of thermal decompositions of d-LMO and d-NCM, $\mathrm{Mn}_{3} \mathrm{O}_{4}$ appears around $225^{\circ} \mathrm{C}$ and grows steadily afterwards. It coexists with d-LMO and d-NCM until around $500{ }^{\circ} \mathrm{C}$, where the 
latter two start to decrease while the rock-salt phases start to grow. Detailed analysis of high temperature XRD pattern reveals that three kinds of rock-salt phases are present (Fig. 4c). Using the method previously discussed, they are identified as $\mathrm{MnO},(\mathrm{Mn}, \mathrm{Co}, \mathrm{Ni}) \mathrm{O}$ and $\mathrm{NiO}$. Since the formation of $\mathrm{NiO}$ is usually associated with abrupt reduction of highly oxidized nickel, its presence may signal more oxygen release than other transition metal oxide counterparts. This is in good agreement with $\mathrm{CO}_{2}$ profile where the high temperature peaks show more complicated features than the previous two cases. Therefore, in the low temperature region (room temperature to $500{ }^{\circ} \mathrm{C}$ ), the thermal stability and phase transition behavior resemble that of pure LMO and $3: 1$; in the high temperature region $\left(>500{ }^{\circ} \mathrm{C}\right)$, more complicated phase transition and thermal instability associated with $\mathrm{NiO}$ formation. Moreover, the onset temperature of $\mathrm{CO}_{2}$ release is further lowered to around $150^{\circ} \mathrm{C}$, following a similar trend to that in previous two cases. This reflects the influence of Ni content on the oxygen loss at early phase transition stage. Such point is also supported by indexing the XRD pattern before heating as shown in Fig. $4 \mathrm{~b}$. It can be seen that those hexagonal peaks gradually broadened and decreased in intensity as temperature was increased, showing similar trend as that in the 3:1 case. All these facts suggest the introduction of NCM into LMO can lower the oxygen release temperature, and this is caused by the poorer thermal stability of the layered structure.

\section{Conclusions}

When LMO was blended with NCM, more complicated rock-salt phases were formed at high temperatures $\left(>500{ }^{\circ} \mathrm{C}\right)$. When the weight ratio of $\mathrm{LMO}$ to $\mathrm{NCM}$ reached $1: 1$, NiO phase appeared, which is different than the LMO to NCM ratio at 3:1, where only $\mathrm{MnO}$ and ( $\mathrm{Ni}, \mathrm{Co}$, $\mathrm{Mn}) \mathrm{O}$, but not pure $\mathrm{NiO}$ appeared. It should be mentioned that introducing $\mathrm{NCM}$ at a ratio of 1:1 
to LMO into the blended material doesn't seem to significantly affect the thermal stability. However, a clearly observed trend is that the more nickel content in the material, the lower onset temperature of oxygen loss (which is suggested by $\mathrm{CO}_{2}$ profile). Such information can be used to provide guidance in optimizing the weight ratio in these blended materials.

\section{Acknowledgement}

This work was supported by the U.S. Department of Energy, the Assistant Secretary for Energy Efficiency and Renewable Energy, Office of Vehicle Technologies under Contract Number DEAC02-98CH10886. Use of the NSLS was supported by the U.S. Department of Energy, Office of Science, Office of Basic Energy Sciences, under Contract No. DE-AC02-98CH10886. MS is supported by a start-up grant from the Hong Kong University of Science and Technology. This work was also supported by the Energy Efficiency \& Resources of the Korea Institute of Energy Technology Evaluation and Planning (Project no. 20142020103090) grant funded by the Korea government Ministry of Trade, Industry \& Energy. The authors appreciate the invaluable discussion with Prof. Jean-Marie Tarascon.

\section{References}

(1) S.B. Chikkannanavar; D.M. Bernardi; L.Y. Liu, J. Power Sources 2014, 248, 91-100.

(2) W.S. Yoon; K.W. Nam; D. Jang; K.Y. Chung; Y.H. Cho; S. Choi; J.C. Hanson; X.Q. Yang, Electrochem. Commun. 2012, 15, 74-77.

(3) H.Y. Tran; C. Taubert; M. Fleischhammer; P. Axmann; L. Kuppers; M. Wohlfahrt-Mehrens, J. Electrochem. Soc. 2011, 158, A556-A561. 
(4) K.W. Nam; W.S. Yoon; H. Shin; K.Y. Chung; S. Choi; X.Q. Yang, J. Power Sources 2009, 192, 652659.

(5) S.T. Myung; M.H. Cho; H.T. Hong; T.H. Kang; C.S. Kim, J. Power Sources 2005, 146, 222-225.

(6) T. Numata; C. Amemiya; T. Kumeuchi; M. Shirakata; M. Yonezawa, J. Power Sources 2001, 97-8, $358-360$.

(7) Z.F. Ma; X.Q. Yang; X.Z. Liao; X. Sun; J. McBreen, Electrochem. Commun. 2001, 3, 425-428.

(8) M.M. Thackeray; P.J. Johnson; L.A. Depicciotto; P.G. Bruce; J.B. Goodenough, Mater. Res. Bull. 1984, 19, 179-187.

(9) H. Kitao; T. Fujihara; K. Takeda; N. Nakanishi; T. Nohma, Electrochem Solid St 2005, 8, A87-A90.

(10) T. Ohzuku; Y. Makimura, Chem. Lett. 2001, 642-643.

(11) O. Schilling; J.R. Dahn, J. Electrochem. Soc. 1998, 145, 569-575.

(12) N. Yabuuchi; T. Ohzuku, J. Power Sources 2003, 119, 171-174.

(13) W.B. Luo; J.R. Dahn, J. Electrochem. Soc. 2011, 158, A428-A433.

(14) W.B. Luo; X.H. Li; J.R. Dahn, Chem. Mater. 2010, 22, 5065-5073.

(15) W.B. Luo; X.H. Li; J.R. Dahn, J. Electrochem. Soc. 2010, 157, A993-A1001.

(16) W.B. Luo; F. Zhou; X.M. Zhao; Z.H. Lu; X.H. Li; J.R. Dahn, Chem. Mater. 2010, 22, 1164-1172.

(17) W.S. Yoon; M. Balasubramanian; X.Q. Yang; J. McBreen; J. Hanson, Electrochem Solid St 2005, 8, A83-A86.

(18) W.S. Yoon; J. Hanson; J. McBreen; X.Q. Yang, Electrochem. Commun. 2006, 8, 859-862.

(19) K.W. Nam; W.S. Yoon; X.Q. Yang, J. Power Sources 2009, 189, 515-518.

(20) K.S. Lee; S.T. Myung; D.W. Kim; Y.K. Sun, J. Power Sources 2011, 196, 6974-6977.

(21) E.Y. Hu; S.M. Bak; J. Liu; X.Q. Yu; Y.N. Zhou; S.N. Ehrlich; X.Q. Yang; K.W. Nam, Chem. Mater. 2014, 26, 1108-1118.

(22) K.W. Nam; S.M. Bak; E.Y. Hu; X.Q. Yu; Y.N. Zhou; X.J. Wang; L.J. Wu; Y.M. Zhu; K.Y. Chung; X.Q. Yang, Adv. Funct. Mater. 2013, 23, 1047-1063. 
(23) S.M. Bak; K.W. Nam; W. Chang; X.Q. Yu; E.Y. Hu; S. Hwang; E.A. Stach; K.B. Kim; K.Y. Chung; X.Q. Yang, Chem. Mater. 2013, 25, 337-351.

(24) A.C. Larson; R.B. Von Dreele, LANSCE, MS-H805, 1994.

(25) B.H. Toby, J. Appl. Crystallogr. 2001, 34, 210-213.

(26) S.C. Yin; Y.H. Rho; I. Swainson; L.F. Nazar, Chem. Mater. 2006, 18, 1901-1910.

(27) J.D. Dunitz; L.E. Orgel, J. Phys. Chem. Solids 1957, 3, 318-323.

(28) J.B. Goodenough; A.L. Loeb, Phys. Rev. 1955, 98, 391-408.

(29) F.C. Romeijn, Philips Res. Repts 1953, 8, 304-320.

(30) D.G. Wickham, Journal of Inorganic \& Nuclear Chemistry 1964, 26, 1369-1377.

(31) F.J. Morin, Bell Syst. Tech. J. 1958, 37, 1047-1084.

(32) J.C. Hunter, J. Solid State Chem. 1981, 39, 142-147.

(33) C.K. Lin; Y. Piao; Y.C. Kan; J. Bareno; I. Bloom; Y. Ren; K. Amine; Z.H. Chen, ACS Appl Mater Inter 2014, 6, 12692-12697.

(34) Z.H. Chen; Y. Ren; E. Lee; C. Johnson; Y. Qin; K. Amine, Adv Energy Mater 2013, 3, 729-736.

(35) Mattheiss.LF, Phys. Rev. B 1972, 5, 290-306.

(36) W.B. Pearson, A handbook of lattice spacings and structures of metals and alloys. Pergamon Press, New York, 1958. 


\section{Figure captions:}

Figure 1. Charging profiles of blended cathode materials with different weight ratios.

Figure 2. (a) In situ XRD-MS data of electrochemically delithiated LMO, and (b) LeBail fitting of the XRD pattern at $580{ }^{\circ} \mathrm{C}$.

Figure 3. (a) In situ XRD-MS data of electrochemically delithiated LMO and NCM mixture with weight ratio of $3: 1$, and (b) zoomed in XRD patterns with $(h k l)_{\mathrm{H}}$ and $(h k l)_{\mathrm{C}}$ indexed for hexagonal NCM and cubic LMO respectively; patterns are only shown up to $300^{\circ} \mathrm{C}$ for clarity. (c) LeBail fitting of the XRD pattern at $580{ }^{\circ} \mathrm{C}$. *rock salt phases include $\mathrm{MnO}$ and $(\mathrm{Mn}, \mathrm{Co}, \mathrm{Ni}) \mathrm{O}$; their forming temperatures are close to each other.

Figure 4. (a) In situ XRD-MS data of electrochemically delithiated LMO and NCM mixture with weight ratio of $1: 1$, and (b) zoomed in XRD patterns with $(h k l)_{\mathrm{H}}$ and $(h k l)_{\mathrm{C}}$ indexed for hexagonal NCM and cubic LMO respectively; patterns are only shown up to $250^{\circ} \mathrm{C}$ for clarity. (c) LeBail fitting of the XRD pattern at $580{ }^{\circ} \mathrm{C}$. $* *$ rock salt phases include $\mathrm{MnO},(\mathrm{Mn}, \mathrm{Co}, \mathrm{Ni}) \mathrm{O}$ and $\mathrm{NiO}$; their forming temperatures are close to each other. 


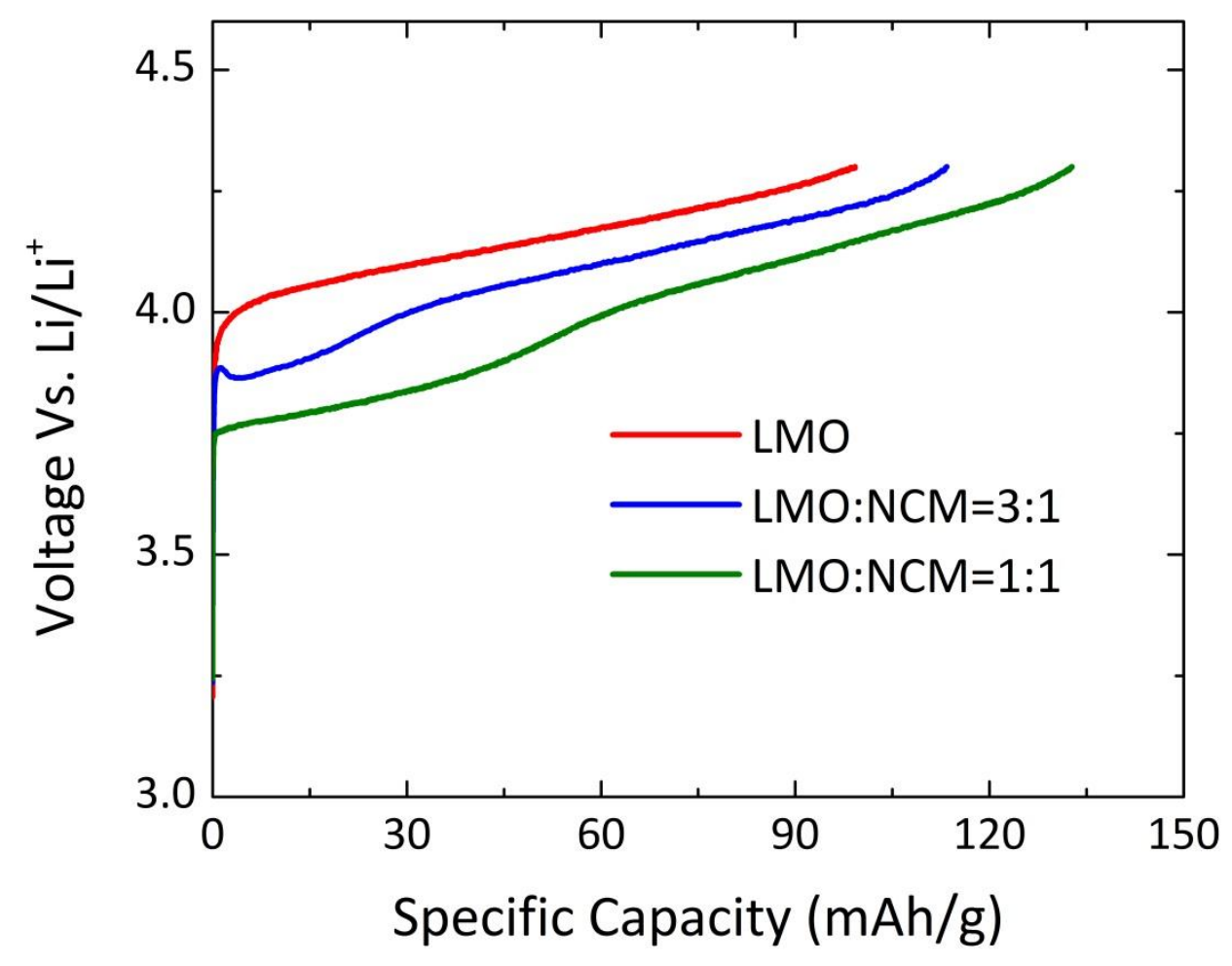

Figure 1. 


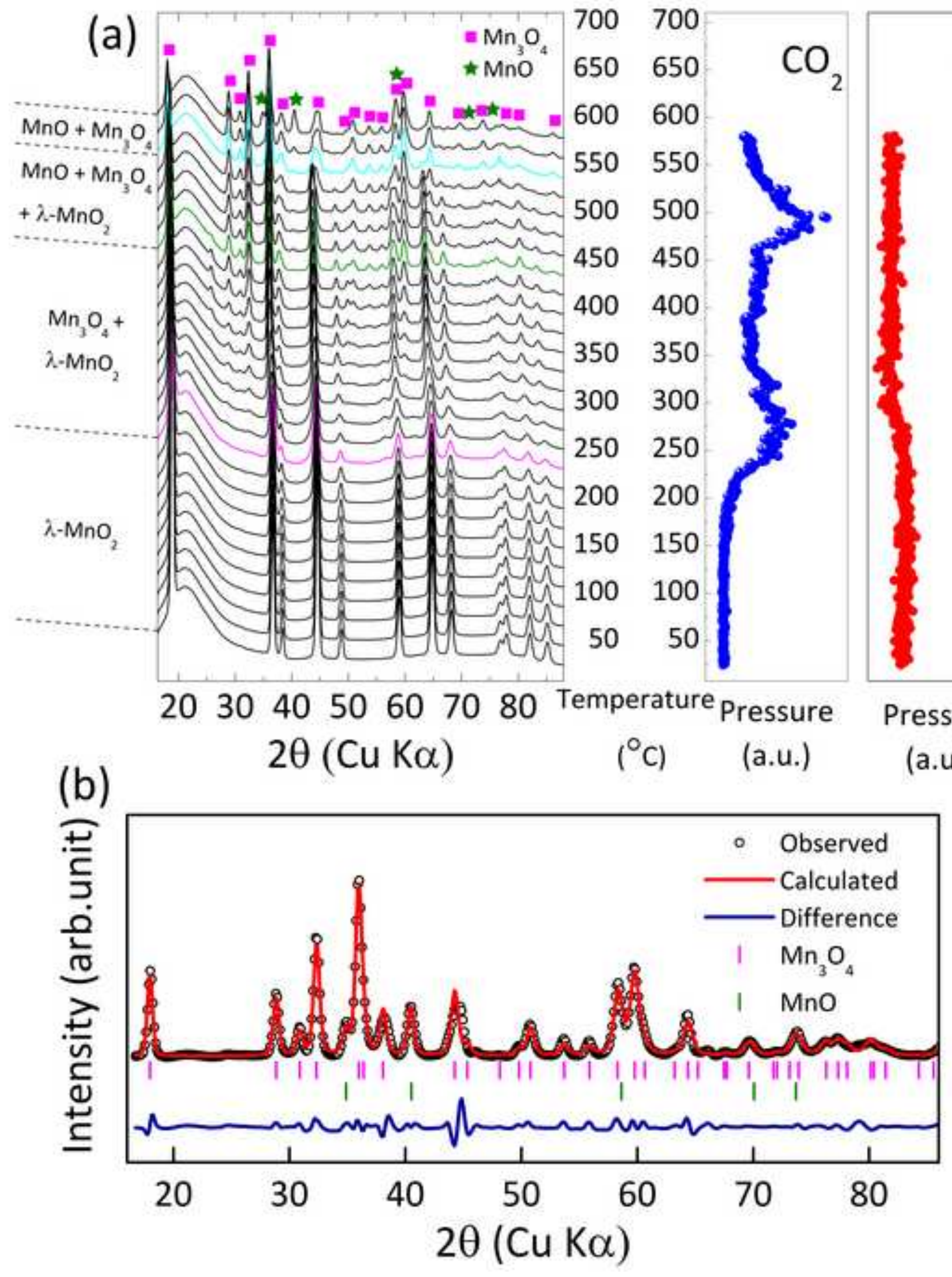




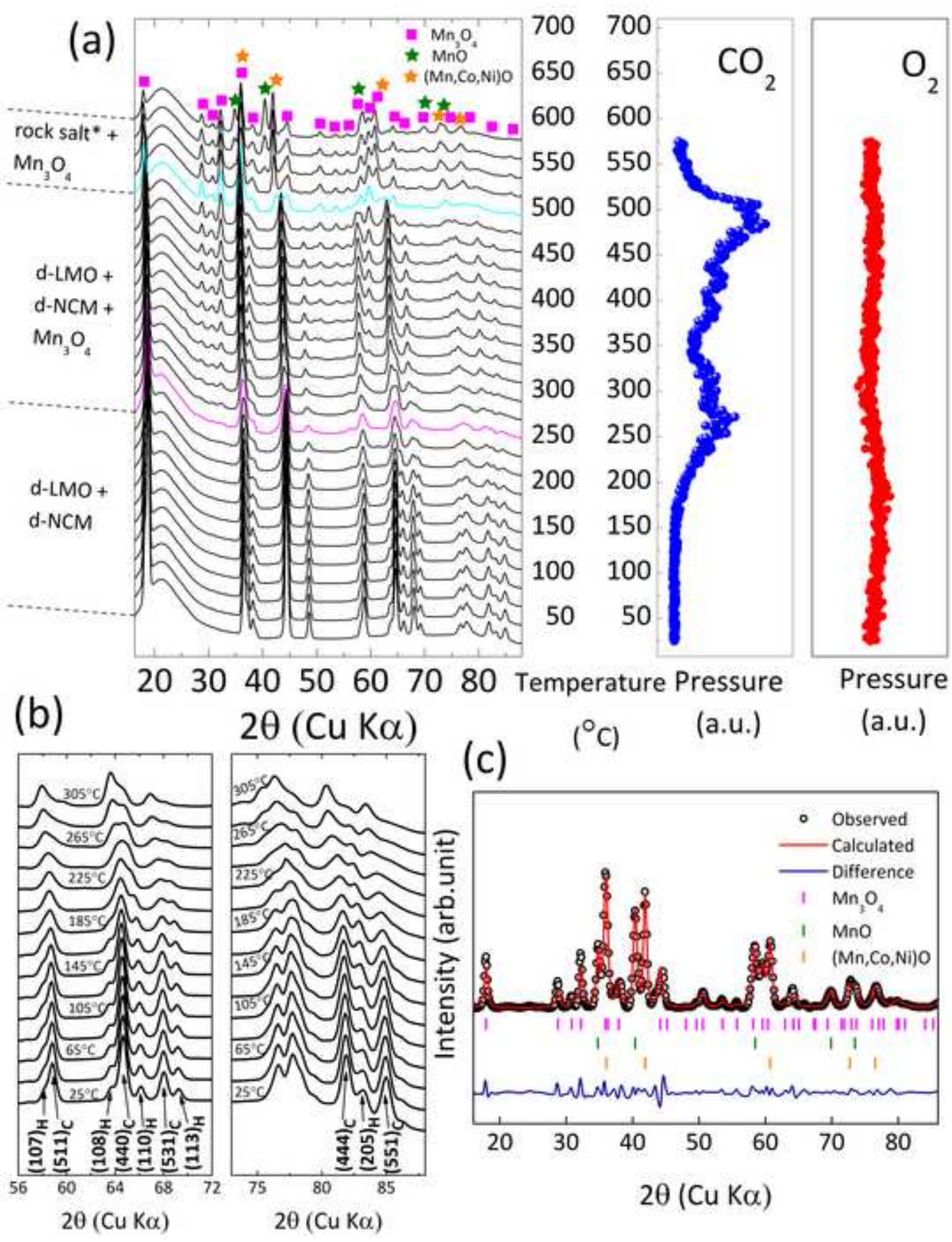

$2 \theta(\mathrm{Cu} \mathrm{K} \alpha)$ (a.u.) 


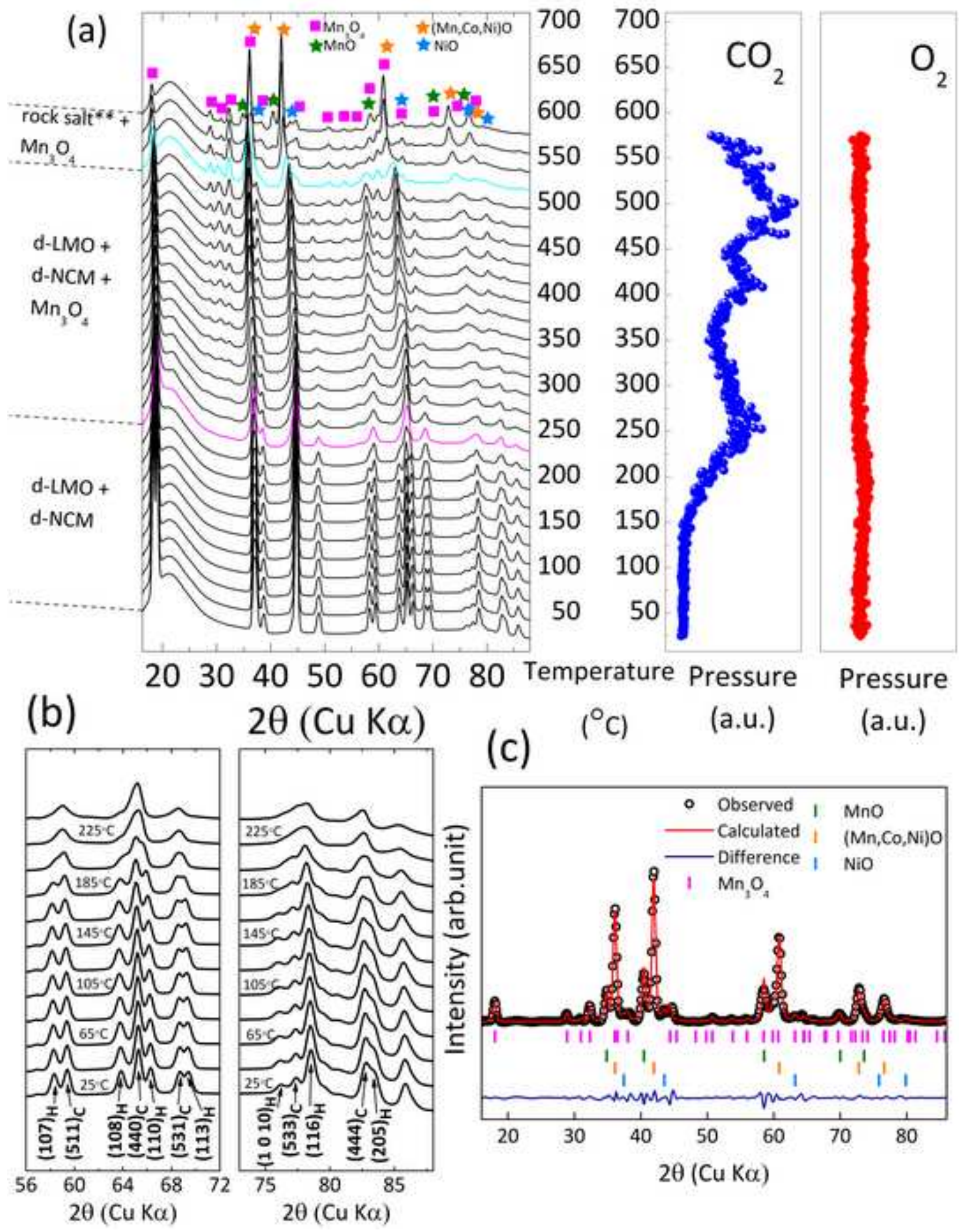

